18-20 December, 2020

Oxford, United Kingdom $11^{\text {th }}$ International Conference on

Humanities, Psychology \& Social Sciences

\title{
Conceptual foundations for the formation of social competence of high school students
}

\author{
Bushnaya Natallia, \\ Minsk, Belarus
}

\begin{abstract}
.
The ability or inability of high school students to cope with a variety of social problems and to realize themselves in the society due to their solution indicates availability or lack of social competence. The article presents the essence, framework, functions and conceptual regulations of the formation of social competence of high school students. Social competence of high school students is presented as an integrative characteristic of high school students and acts as the result of education. Three components form the framework of social competence of high school students: motivational and valued, cognitive and operational. The formation of social competence of high students is realized in the school educational space by means of solving social tasks of individual-personal, public, life-futurological content. The conceptual regulations of the formation of social competence of high school students are presented by values, patterns, principles and norms. Practical significance of the proposed conceptual foundations lies in the fact that it provides an increase in the high school student's subjectivity in the course of formation of social competence by means of identifying his position, self-development and self-realization in school educational space solving social tasks lying in the field of social significance, personal orientation and life prospects.
\end{abstract}

Key words: social competence, social problems of personal, public and lifefuturological content.

\section{Introduction}

The dynamics of socio-cultural processes and fundamental changes in the world information space has revealed global problems of the XXI century that challenge humanity. Accessibility of any information, expansion of the life environment, increasing the degree of freedom, complication of social ties, relationships, problems these are the challenges that education must respond to.

Employers demand graduates that are able to operate in complex environments, that is in environments characterized by contradictory information, informal collaboration and abstract dynamic and highly integrated processes (Westera, 2001). The readiness and ability of school graduates to self-determination and selfrealization in the new conditions of sociality of the XXI century is largely due to their social competence. This explains the high demands of society and the state for the formation of social competence of high school students.

At the age of completion of general secondary education, students face problems of self-identification, forming an adequate orientation towards various social 


\section{8-20 December, 2020}

\section{Oxford, United Kingdom}

\section{$11^{\text {th }}$ International Conference on Humanities, Psychology \& Social Sciences}

phenomena and situations, determining their place in the system of social relations, professional and life self-determination. The ability of high school students to cope with various social problems and through their resolution to realize themselves in society, we associate with the presence of their formed social competence.

In relation to modern high school students, the problem of social competence formation has not been sufficiently studied and there is a lack of effective conceptual foundations for this process that meet the challenges of education in the XXI century. All this defines the urgency of developing conceptual bases of formation of social competence of pupils in school educational space in accordance with modern approaches and requirements to organization of educational practices.

\section{Methodology}

The essence of a person's social competence is revealed in psychology (M. Argyle, J. Bowlby, R. Hinsch, G. Zilger, W. Pfingsten, L. Rose-Krasnor, K. Rubin, M. Forverg, M. Ford, F. Hellman, R. Hinsch, G. Zimmer, G. Belitskaya, E. Koblyanskaya, V. Kunitsina, A. Savenkov, etc.). Taking into account age, the process of forming social competence of students is revealed in the studies of O. Borisova (Preschool); O. Galakova J. Korotina, O. Kruse-Bruks (Junior school); L. Gienko, T. Samsonova (adolescent).

The results of theoretical and empirical research of the phenomenon of social competence of high school students give reason to interpret it as the need, readiness and ability of high school students to solve social problems in the unity of social and personal significance on the basis of formed knowledge and skills, experience of independent social practice. The need determines the motivational and value aspect of high school students' social competence, readiness determines its cognitive resource, and ability - the aspect that is directly manifested in its activity.

The motivational and value component of social competence of high school students is expressed in achievement motives (McClelland et al., 1953), the motives of self-development of social competence, inclusion in various activities to achieve socially significant goals, social interaction, correlation of their personal values with the values of society. The need to build social relationships, solve social problems for the benefit of oneself and the social environment and design one's future indicates stable positive dynamics of the motivational and value component of a high school student's social competence.

The cognitive component of social competence creates the platform that allows high school students to navigate the social reality, to recognize themselves as active subjects of self-development in this area and to ensure their readiness to solve social problems and build social relationships. It is formed through the acquisition and development of knowledge about self-knowledge and self-development, about the structure of social institutions and social reality in general, about social interaction (in a group, class, team, society), achieving socially and personally significant results of activities, designing their future, etc. The positive dynamics of the formation of this component of social competence implies the movement from high school students' possession of ready-made algorithms and scenarios of social knowledge to their creative application in situations of uncertainty and ambiguity. 


\section{8-20 December, 2020}

Oxford, United Kingdom

\section{$11^{\text {th }}$ International Conference on Humanities, Psychology \& Social Sciences}

We consider social activity as a defining characteristic of the operational component of high school students' social competence. Social activity of a high school student is a specific measure of his social activity, the degree of realization of his communicative and organizational abilities, direct involvement in various activities based on the harmonization of formed motives, value orientations and perceived social reality. In assessing the formation of this component, it is necessary to focus on the dynamics of autonomy of high school students in the implementation of their social activity.

The profile of achievements should be reported not only at entrance but at various points throughout the schooling to give teachers, administrators, and students feedback on whether growth in desired characteristics actually is occurring (McClelland, 1973).

\section{Results and Discussion}

The formation of a young person's need, readiness and ability to cope with social problems and resolve social situations occurs through setting and solving certain tasks. Therefore, it is important to determine the typology and content of social tasks in which the social competence of high school students finds its real embodiment. It is possible to do this by focusing on the main functions of social competence in high school age.

According to the socio-anthropological characteristics of high school students and the society's request for the personality of a school graduate who is ready and able to realize himself outside of classes and educational programs in a modern social environment, we consider adaptation, personal growth, achieving a balance between personal and socially significant goals, self-actualization and self-realization, and life self-determination as the main functions of social competence in relation to the age of high school students. These functions of social competence determine the content of social tasks through which high school students form social competence. These are tasks that are designed to enrich the experience of a high school student with technologies for personal development, technologies for working in a group, team, society, as well as technologies that allow you to design your life.

Based on the above, we distinguish three groups of social tasks - individualpersonal, public and life-futurological content - that determine the content of the educational space of the school.

The formation of social competence of high school students in the educational space of the school is based on conceptual regulations that guide in determining the goals of the educational process and the mechanisms for achieving them. The latter are revealed through the values, patterns, principles and norms, in accordance with which the process of forming the social competence of high school students in the educational space of the school is built.

The axiological basis of the concept is determined by the values that set the goalthe result of the process under study, and the values that guide the choice of mechanisms for achieving the goal. The first group of values is meaningful and reflects the desire of high school students to acquire the qualities of a socially competent person for successful self-realization in society. These values serve as the 


\section{8-20 December, 2020}

\section{Oxford, United Kingdom}

\section{$11^{\text {th }}$ International Conference on Humanities, Psychology \& Social Sciences}

basis for the formation of social competence of high school students in the unity of its motivational-value, cognitive and operational components. The second group of values serves as a reference point in determining the mechanisms of formation of social competence of high school students in the educational space of the school. The mechanisms are designed to stimulate the motivation of high school students to achieve, include them in developing interaction with various subjects of the educational space based on creativity and innovation, increasing reflection by high school students of the social significance of their personality, and building up their social skills.

The formation of social competence of high school students in the educational space of the school will be successful if the educational process is based on the following patterns:

- the level of formation of social competence is directly dependent on the involvement of high school students in practical activities to solve social tasks in which the essence of social competence finds its real embodiment;

- social tasks that form the social competence of high school students are in the field of social significance, personal meaning and life prospects in the unity of their individual-personal, public and life-futurological content;

- the formation of social competence is due to the stability of the motivational and value sphere of the high school student's personality, which develops in its direction from fragmentary to sustainable interest in solving social tasks;

- the development of social competence is provided by increasing social knowledge from the level of knowledge of ready-made scenarios and algorithms of activity to the creative level that allows you to apply this knowledge in an unfamiliar situation and create new social knowledge yourself;

- the success of forming the social competence of high school students depends on increasing the autonomy of high school students in setting and solving social tasks.

In accordance with the identified patterns, the process of forming the social competence of high school students should be based on the principles determined by them. The principle of social determination implies a socially determined nature of the educational process. This is achieved by designing this process in an orientation towards solving social tasks of individual-personal, public, life-futurological content. The principle of initiative in the formation of social competence of high school students focuses on the organization of the educational space of the school, which creates opportunities for involving students in the independent solution of social tasks. The principle of dialogue is based on understanding the other person and openness in communication. It allows you to identify, relate and link the values of various subjects of the school's educational space. Dialogue is one of the most important means of developing the ability of high school students to constructively resolve situations of ambiguity and uncertainty, identify social problems, and determine ways to solve them.

The principle of subjectivity requires relying on the personal experience of high school students, which forms the ability to independently design and implement ready-made and create new algorithms of actions that lead to solving social problems. Subjectivity determines the reflexivity of one's own actions, non-determinism of behavior by external influences, and forms the ability to make responsible choices. 


\section{8-20 December, 2020}

Oxford, United Kingdom

\section{$11^{\text {th }}$ International Conference on Humanities, Psychology \& Social Sciences}

The principle of problem-solving is implemented in the process of mastering the material in the classroom and is deployed in all types of activities for solving social tasks, which include a high school student in the educational space of the school. The principle of coherence requires achieving consistency in the formation of social competence in time and space.

The principles allow you to define pedagogic norms for the formation of social competence of the pupils:

the formation of social competence of the pupils acts as an organic element of a holistic educational process of the school;

the educational process is based on the transformation of knowledge, skills and abilities into beliefs, meanings and value orientations that allow high school students to cope with various social problems;

the formation of social competence of high school students occurs through solving social tasks that are in the field of social significance, personal meaning and life prospects;

setting and solving social tasks are provided by semantic variability, event-based interaction of high school students with other subjects of the school's educational space, the presence of various zones in it, both zones with orientations and zones with situational uncertainty;

formation of social competence is accompanied by the increase of subjectivity of students in the development of educational space of the school in orientation from self-determination to self-realization through self-development, which is based on the experience of effective social action and the increasing role of reflection in selfaddressing seniors' social issues;

to develop the stability of the motivational and value sphere, to go beyond the limits of subject knowledge, to learn new, unknown knowledge, to take the initiative in setting and independently solving social problems, it is possible to focus on innovation and creativity.

\section{Conclusion}

Thus, the social competence of a high school student is an integrative personal characteristic that reflects the need, readiness and ability of a high school student to solve social problems from the position of personal significance, norms and values of society by solving tasks of individual-personal, public and life-futurological content that ensure his self-realization in society.

The formation of social competence of high school students takes place in the educational space of the school, taking into account the patterns, principles and norms described in the article. As a result, all activities that involve high school students acquire the character of collectively organized social creativity, and students themselves become subjects of development of their social competence by setting and solving social tasks at the stages of self-determination, self-development and selfrealization in the educational space of the school.

\section{Acknowledgement}


18-20 December, 2020

Oxford, United Kingdom $11^{\text {th }}$ International Conference on Humanities, Psychology \& Social Sciences

The author would like to thank Professor H. V. Torkhava for useful recommendations and valuable advice on the preparation of the article.

\section{References}

1. McClelland, D. C., Atkinson, J. W., Clark, R. A., \& Lowell, E. L. (1953). The achievement motive, Appleton Century-Crofts, New York.

2. McClelland, D. C. (1973). Testing for competence rather than intelligence, American Psychologist. [Online]. 28(1), pp. 22-26. Available: https://www.therapiebreve.be/documents/mcclelland-1973.pdf

3. Westera, W. (2001). Competences in Education: A Confusion of Tongues. Journal of Curriculum studies. [Online]. 33(1), pp. 75-88. Available: https://www.researchgate.net/publication/230557879_ 